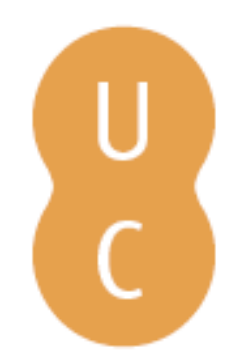

\title{
nombalina
}

\section{Mobile Applications and its Potential to Maintenance}
Autor(es):
Santos, Hugo; Simões, António; Fonseca, Inácio; Farinha, Torres
Imprensa da Universidade de Coimbra; Faculdade de Ciências e
Publicado por: Tecnologia da Universidade de Coimbra, Departamento de Engenharia Mecânica
persistente:
DOI: $\quad$ DOI:http://dx.doi.org/10.14195/978-972-8954-42-0_15
Accessed : $\quad$ 26-Apr-2023 14:33:21

A navegação consulta e descarregamento dos títulos inseridos nas Bibliotecas Digitais UC Digitalis, UC Pombalina e UC Impactum, pressupõem a aceitação plena e sem reservas dos Termos e Condições de Uso destas Bibliotecas Digitais, disponíveis em https://digitalis.uc.pt/pt-pt/termos.

Conforme exposto nos referidos Termos e Condições de Uso, o descarregamento de títulos de acesso restrito requer uma licença válida de autorização devendo o utilizador aceder ao(s) documento(s) a partir de um endereço de IP da instituição detentora da supramencionada licença.

Ao utilizador é apenas permitido o descarregamento para uso pessoal, pelo que o emprego do(s) título(s) descarregado(s) para outro fim, designadamente comercial, carece de autorização do respetivo autor ou editor da obra.

Na medida em que todas as obras da UC Digitalis se encontram protegidas pelo Código do Direito de Autor e Direitos Conexos e demais legislação aplicável, toda a cópia, parcial ou total, deste documento, nos casos em que é legalmente admitida, deverá conter ou fazer-se acompanhar por este aviso.

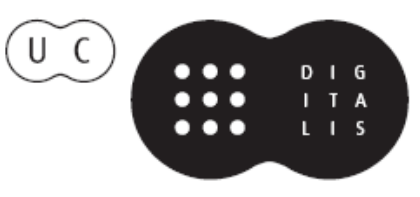




\title{
Mobile Applications and its Potential to Maintenance
}

\author{
${ }^{1}$ Hugo Santos, ${ }^{2,3}$ António Simões, ${ }^{1,3}$ Inácio Fonseca, ${ }^{2,3}$ Torres Farinha \\ hugombsantos@hotmail.com; \\ ${ }^{1}$ Electrical Engineering Department; ${ }^{2}$ Mechanical Engineering Department; ${ }^{3} \mathrm{CEMUC}$ \\ Coimbra, Portugal
}

\begin{abstract}
Mobile technology is constantly evolving, most notably following the advent of Smartphone technology. As this equipment becomes faster, more powerful, and less expensive, it will become an excellent platform for the development of ergonomic and effective maintenance tools.

The present article describes an application that allows for an easy, organized and systematic way of improving the process of recording physical equipment data within the field of maintenance management, thus making the following contribution one of immense value to the field by increasing the accuracy of data storage.

The first, and arguably the most crucial step, necessary to elaborating the equipment dossier is to register its intrinsic data, planning data, and so on. Although, this phase is perceived as the easiest, it is usually one of the weakest points in equipment registering.

Having this issue in mind, an application was developed in order to facilitate equipment registering. The ultimate goal was to increase the efficiency of the registering process and equipment dossier, in addition to the processes involved during maintenance management. The present approach also aims to demonstrate that it is possible to develop effective maintenance via low-cost tools that do not require specialized equipment to function effectively. Mobile applications provide a huge opportunity to improve the working conditions experienced by maintenance teams.

From the initial process of regularly organizing workplace equipment, to operation issues when carrying out work orders, mobile technology can help improve the efficiency of various processes. The application allows effective and systematic way to improve the process of recording equipment, and is designed for mobile devices running Android (Google's system), or industrial equipment like PDAs running windows mobile - for example the Lynx model from Datalogic.
\end{abstract}

Keywords — Mobile applications; Maintence; Equipment dossier

\section{INTRODUCTION}

Mobile applications have a huge opportunity to improve the working conditions of maintenance teams, presently, there exists a void in available applications that use Smartphone devices. However, some companies have already begun to provide some products in this area, like Yardi [5] its mobile solutions allow completion of maintenance and inspection tasks, access to approve invoices and purchase orders, and also companies like RealPage [4] with its OneSite Facilities Mobile Service[9], which automates the whole process of maintenance performed by a technician through an easy management of all maintenance requests and Work Orders
(WO). Thereby, reducing the time spent managing the entire documentation generated by the aforementioned process while also increasing technician productivity, by allowing for new WO to be received on site. In the field of wireless categorization of inventory it is possible to find solutions such as MobileAsset v7 and MobileAsset.EDU from the company Wasp Barcode Technologies [7]. These solutions offer a complete cataloging system that includes servers, an advanced management interface for standard computers, built-in communication with industrial equipment (capable of reading barcodes), and Smartphone applications for Android or iOS devices to access information from a database.

Using some of these ideas and concepts an application was developed to demonstrate various possibilities offered by Smartphone mobile systems in the maintenance field.

\section{VALUE-ADDED TO THE MAINTENANCE FIELD}

The main issue that exists in the maintenance field is that of data loss, following and in between scheduled maintenance completion and WO fulfillment. In order to counteract this loss, data may be more efficiently managed and stored, during and post-maintenance intervention, via the mobile application referred to in the present paper. The ultimate goal of this mobile application, thus, is to store all WO data immediately following each maintenance action as to avoid 'forgotten' data. Other contributions occur during the interventions, namely when these ones are not planned, because the technician can access on-line a fault diagnosis tool, if it exists.

But the interest of the technology under discussion begins at the moment that equipment is purchased, because it permits technicians to register on-site; including bar-code reading and so on. In fact, a correct registration of the equipment dossier in the working database may be one of the main determinants for a correct evaluation of Life Cycle Cost, including: WO, human resources, materials, and so on.

When an intervention request, in particular, urgent requests needing immediate attention, comes about a digital tool, such as a tablet or similar device may facilitate the completion of working orders received by a technician without loss of time. Furthermore, the introduction of new technologies (Augmented Reality, 3D models, Expert Systems, and to name a few) and applications creates synergies in order to minimize intervention time, increase quality, minimize risks, and maximize availability. 


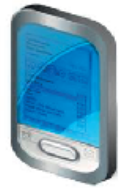

Mobile Side

\section{HTTP Request}

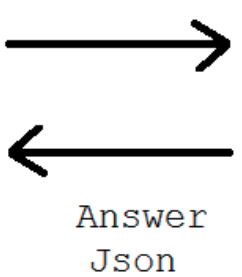

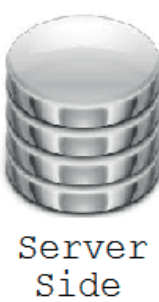

Side
Fig.1. Interaction between the server side and the Mobile side.

\section{GENERIC MOdEl FOR A MoBILE APPLICATION}

This application can be separated in two main categories, which include the server side, where all information is stored and processed, and the mobile side where all information is accessed or entered (Fig.1).

The server component runs a Rest server (Fig. 2) that receives and manages all requests to the server. This Rest server is a PHP script, which is able to receive HTTP requests, either GET or POST requests, and it is able to respond in XML, HTML or JSON. The Rest server is also used as a form of security because it sits between the database and all requests from the outside, not allowing direct access to the main database. The database should be sql type as it allows for easy development and integration with the Rest server.

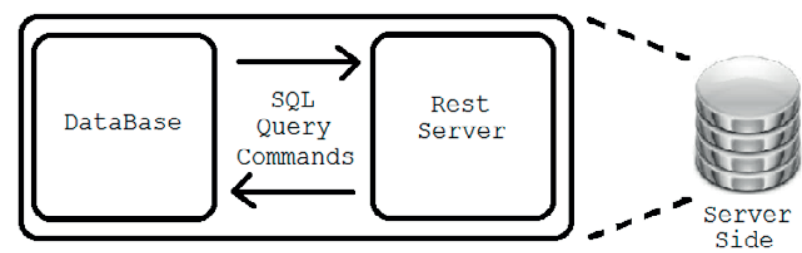

Fig. 2. Server Side Diagram

The mobile side must be able of connecting to the network via Wireless or via GPRS to obtain all the information needed. The device must also be capable of reading barcodes, this can be achieved through image capture or scanning, which requires the mobile to have a camera or a laser scan. The device must also have in his hardware list a touch screen sensitive enough to capture signatures as well as a camera to take photos and store them on the database. In some instances a GPS system may be useful to register the location of the device. In addition to all the listed prerequisites, the mobile device must be able to run an internal database to implement an offline mode. For several years all these features could only be found in expensive industrial devices, such as the PDA Datalogic Lynx, but at present, any Smartphone is capable of fulfilling these requirements. For this reason the author decided to use a PDA and Smartphone for the aforementioned research.

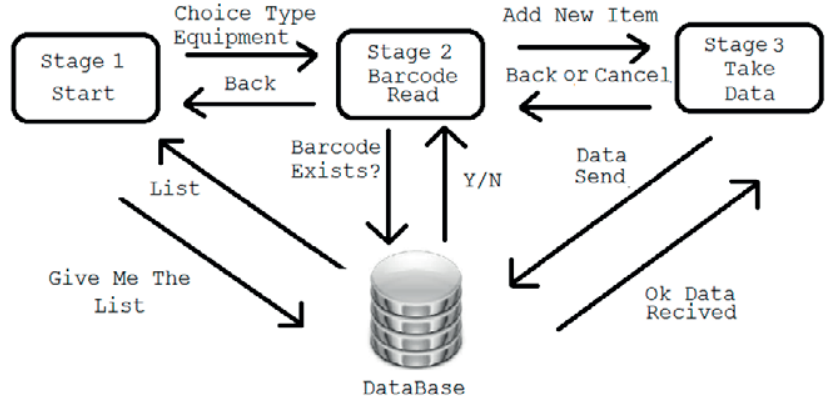

Fig. 3. Basic scheme of functioning of the application.

Once the mobile device is activated the application should check if the device is connected to the network, and that the server is functional. After this initial check, the application should ask the server for a complete list of all perishable equipment. After the list is displayed, the user needs to select the particular item that he wants to catalog.

\section{Stage 1}

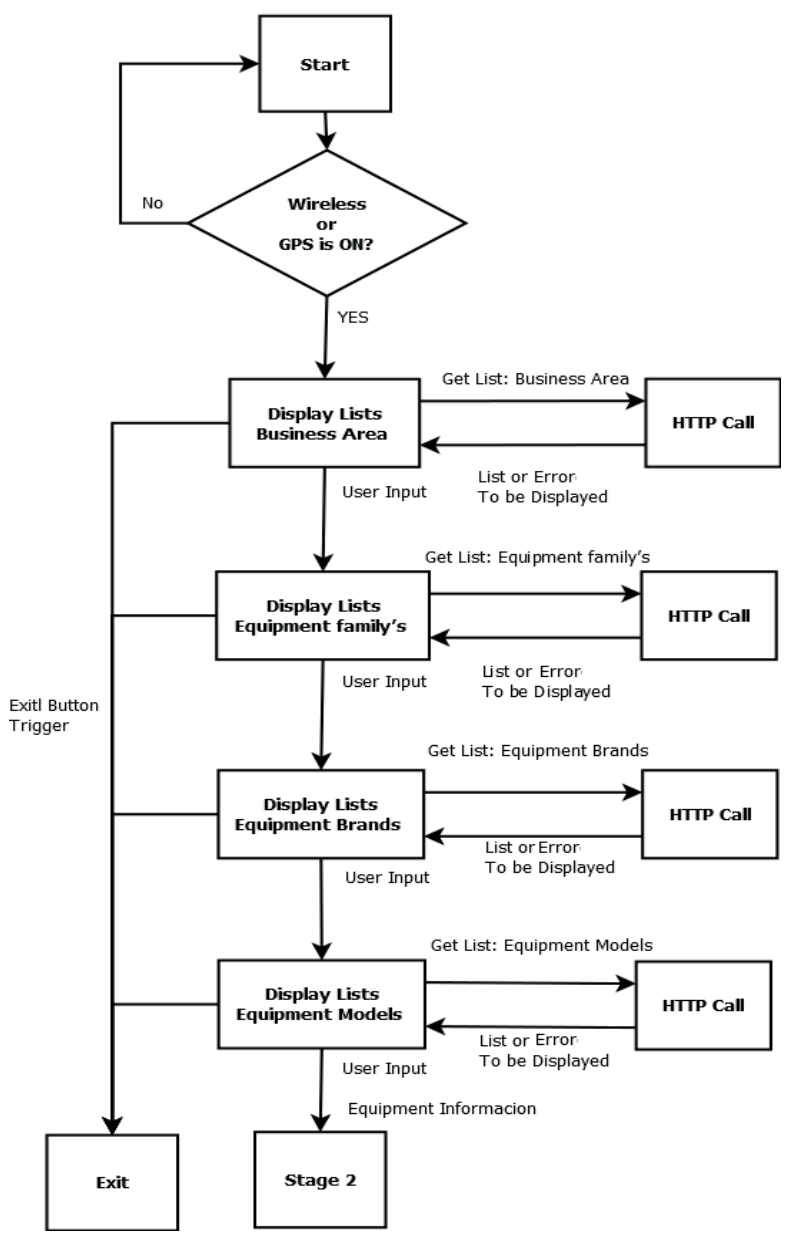

Fig. 4. Flowchart of Stage 1 
In the next stage, the application can be used to scan barcodes, or input them manually, asking the database if the barcode has already been input. If so, the application will ask the user if he intends to overwrite the previous entry. In the event that the user wishes to overwrite the previous entry, or the input is a new entry, the application should jump to its third stage.

\section{Stage 2}

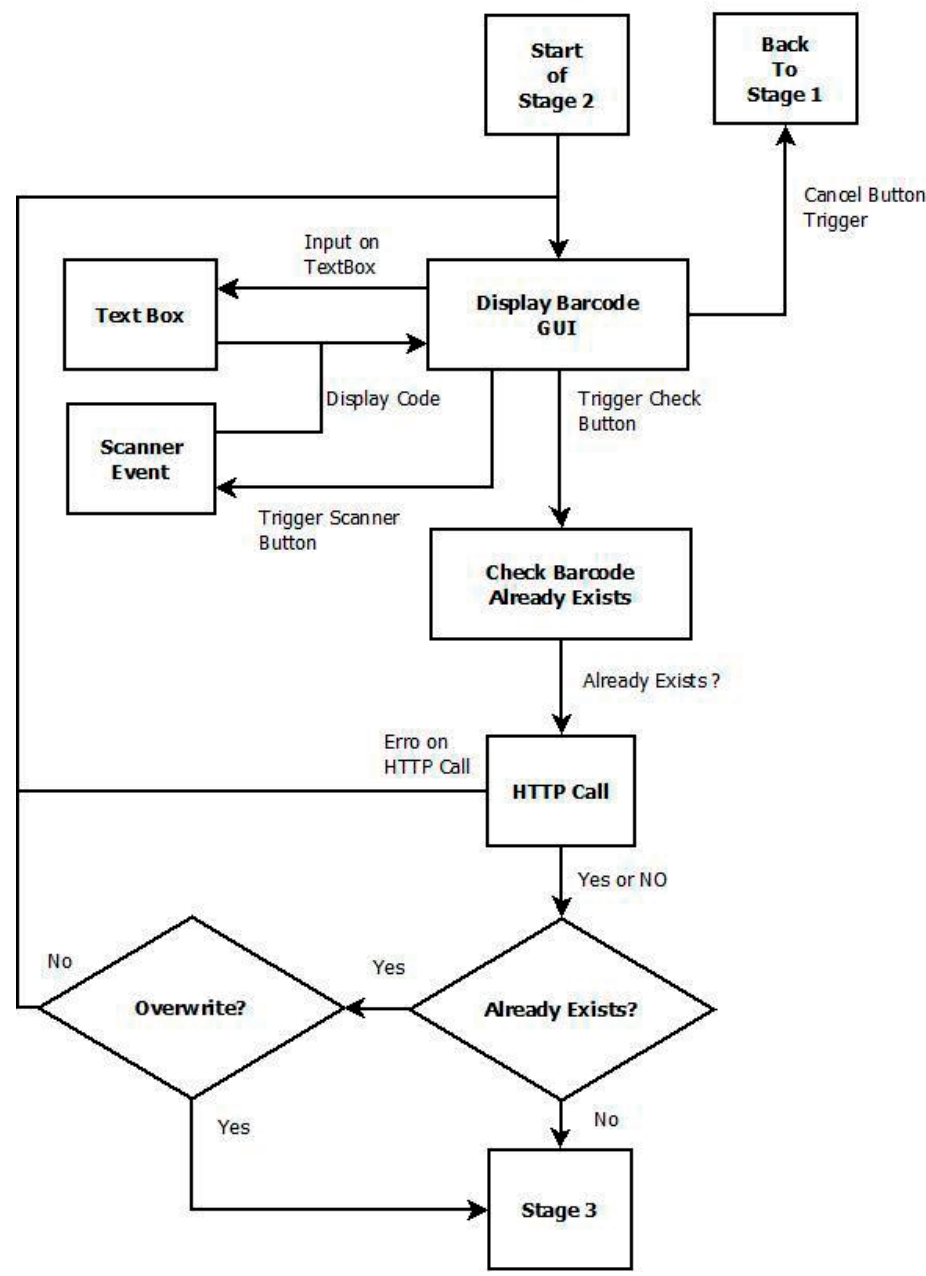

Fig. 5. Flowchart of Stage 2

In the third stage, the user should collect photos, information about the location of equipment, comments regarding the state of the documented equipment, and etcetera, finally obtaining the user's signature. Note that in the case of indoor activity, the GPS function is not the ideal method to determine the device's location. So other means must be found, for example, through the use of a unique ID room system that can be either manually inputted or introduced as a barcode tag.
After all the aforementioned information has been collected, data should be sent to and then processed by the server. Following this action, the application should revert back to stage two - the barcode reading process. This behavior is stated on the following flowcharts (Fig. 3, Fig. 4, Fig. 5 and Fig. 6).

\section{Stage 3}

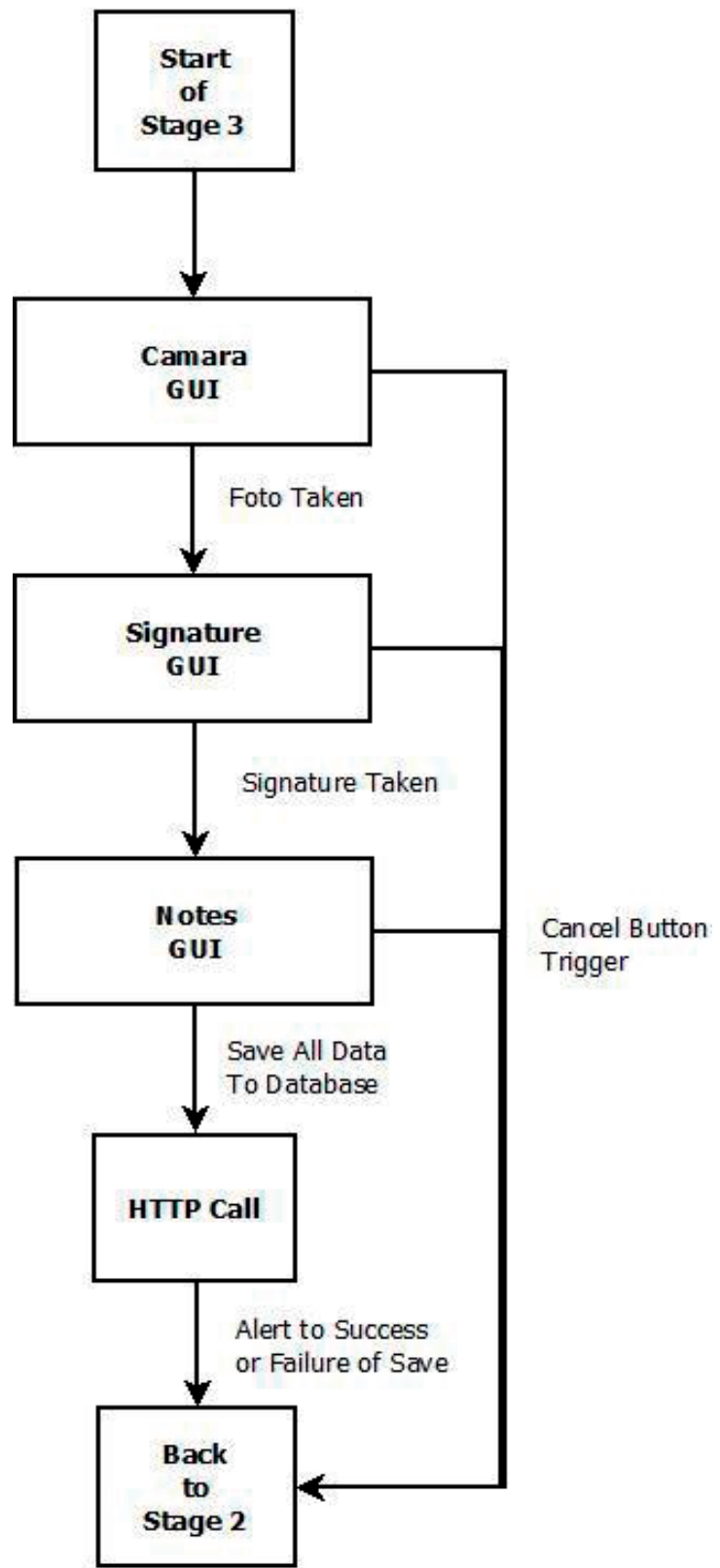

Fig. 6. Flowchart of Stage 3 


\section{PRACTICAL IMPLEMENTATION}

\section{A. Database Implementation}

The database MySQL was integrated with the development environment MySQL WorkBench. By doing so, time was saved, as the whole implementation of the database was developed graphically, a much more intuitive way of database development.

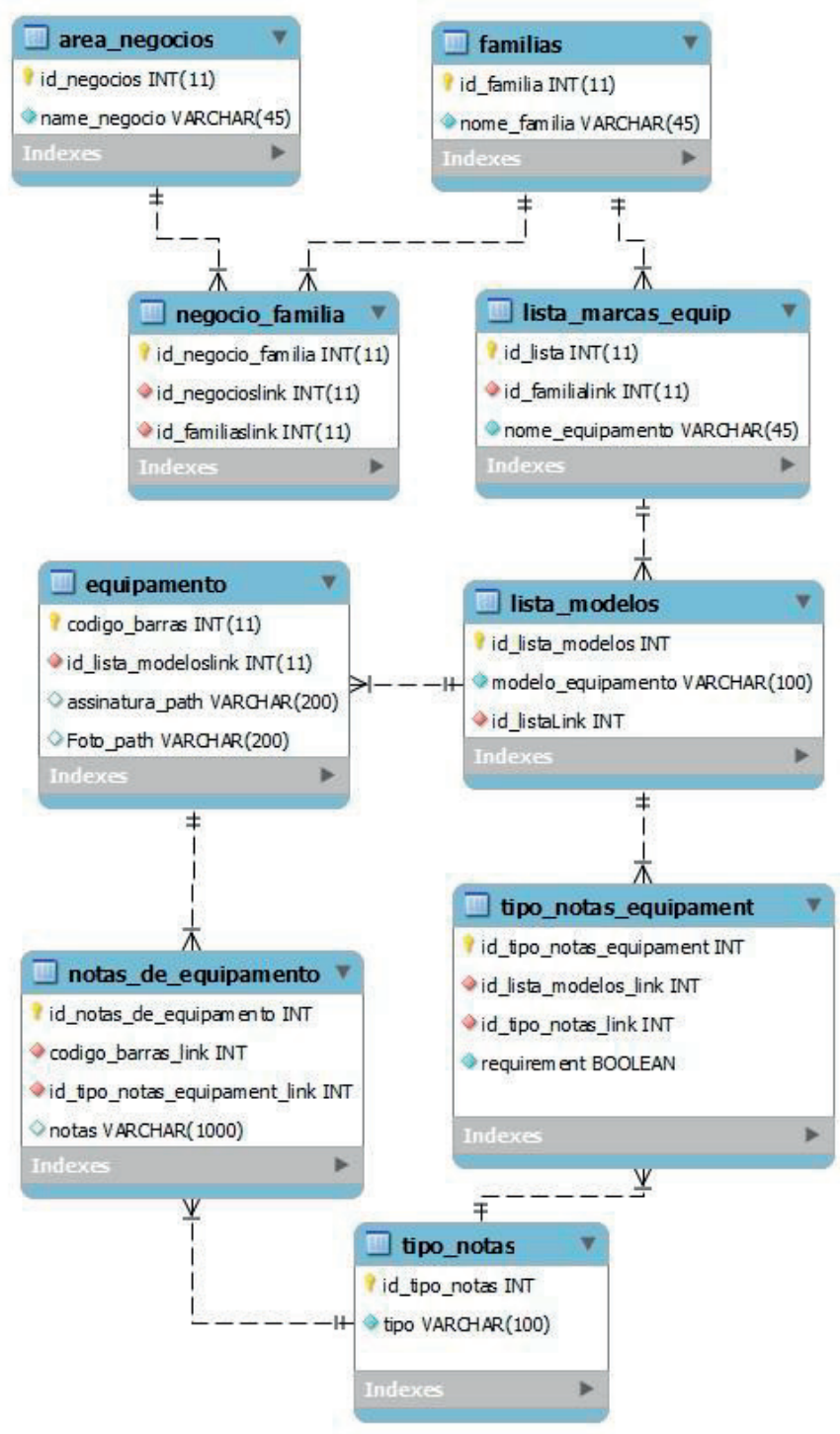

Fig. 7. Database Scheme.

As you can see from Fig. 7, the database is relatively small, containing only nine tables, each one devoted to a specific function.

The database information is organized in the following main areas:
- $\quad$ Business area - table area_negocios;

- Bridge between Business area and Equipment family's - table negocio familia;

- Equipment family's - table familias;

- Equipment brands - table lista_marcas_equip;

- Equipment model - table lista_modeles;

- Bridge between Equipment model and Equipment type notes - table tipo notas equipament;

- Equipment type notes - table tipo_notas;

- Information cataloged - table equipamento;

- Equipment notes taken - table notas_de_ equipamento.

The first seven tables are responsible for the list and sub lists of all the equipment described in the first, initial stage of application. While the two remaining tables are responsible for the storage of all information regarding the cataloged equipment.

\section{B. Rest Server Implementation}

The Representational State Transfer (REST) style is an abstraction of the architectural elements within a distributed hypermedia system [2] [3]. It works by receiving HTTP requests from the mobile device, and acting based on them. Those requests are compose by a web address and the message, they are separated by the character "?" (example: http://192.168.252.207/PDA/rest.v2.php ?accao=autorizacao), as can be seen the message component functions by having a keyword, in this case "accao" and a value "autorizacao", it is also possible to add additional data by adding the character "\&" between messages.

Upon receiving the request, the Rest server should execute the request action. In response, the server should send a message communicating to the device whether the message was a success or failure, in addition to data that was requested by the user. All this information uses the standard RFC 7159 format [1] (this is the JavaScript Object Notation for easy organization and information collection, allowing for friendly handling when receiving data at the mobile application terminal).

\section{Android Implementation}

This mobile application was developed on IDE Eclipse, and debugged on a Samsung GT-S7390, (Fig. 8), with Android version 4.1.2. It was written in Java, the android native language.

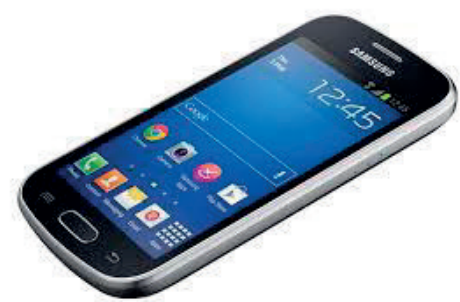

Fig. 8. Samsung GT-S7390 
The aplicacion follows the sequence of information described in Fig. 3, but because the device does not have a laser scanner, it was necessary to find a way to read the barcode via camera. In order to achieve that, a separate application - the Barcode Scanner from Zxing, Fig. 11- was used in combination with the current one to obtain the barcode information. This technique was also recommended by WeiMeng Lee in his book [6].

In Fig. 9 it is possible to see the interface that is available to the user during equipment selection from the catalog (stage 1 of the android application - Choose in sequence: Business Areas, Equipment Family, Marks, and Model). For example: Electronics, Multimeters, AMPROBE, and AM 520 EUR.

\begin{tabular}{|c|c|c|c|}
\hline \multicolumn{2}{|c|}{ '్̂, Rest Call V4 } & \multicolumn{2}{|c|}{ 암 Rest Call V4 } \\
\hline \multicolumn{2}{|c|}{ Business Areas } & \multicolumn{2}{|c|}{ AMPROBE } \\
\hline Computers & (3) Item's & \multirow[t]{2}{*}{ M 520 EUR } & \multirow[t]{2}{*}{ (8) Item's } \\
\hline Electronics & (4) Item's & & \\
\hline Energy & (2) Item's & \multicolumn{2}{|c|}{ You Want To add New Item? } \\
\hline Health & (0) Item's & No & Yes \\
\hline teste1 & (0) Item's & & \\
\hline \multirow[t]{2}{*}{ teste2 } & (0) Item's & & \\
\hline & & \multicolumn{2}{|c|}{ You choice AM 520 EUR } \\
\hline
\end{tabular}

Fig. 9. Display of Equipment List on Android

The display in Fig. 10 and Fig. 11 are where the user can trigger the Barcode Scan activity by pushing the scan button "Start Scan" on the GUI, or manually introduce barcode data in textbox (stage 2).

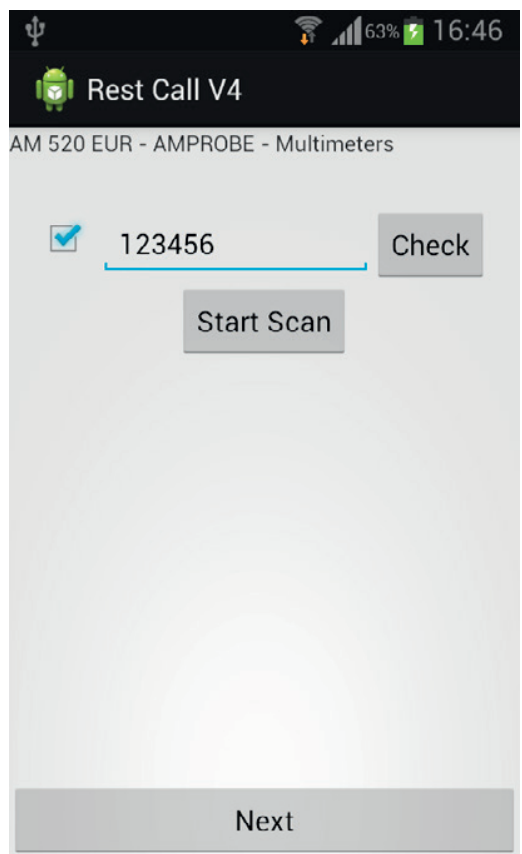

Fig. 10. Display to introduce the barcode on Android

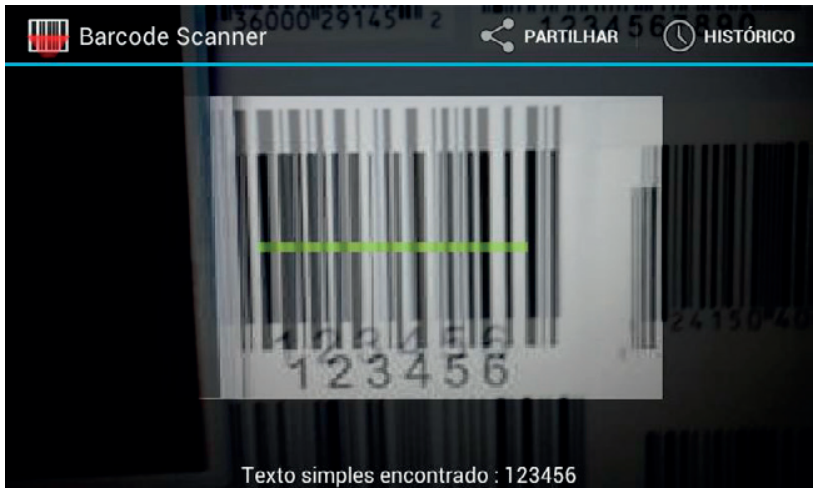

Fig. 11. Barcode Scanner From Zxing.

After the database approves the barcode, and the user presses the "Next" button, the application should begin to gather information about the equipment; first, photos and signature, and then in the tab notes the user can insert other valuable information like location and power supply (see tab interface, Fig. 12 and Fig. 13). 


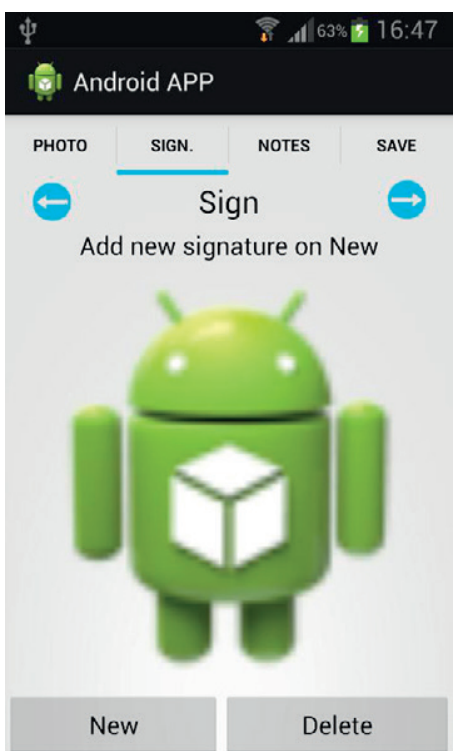

Fig. 12. GUI interface for user take photos and signature.

Here the user can choose to take photos, signatures or take notes about the item, as can be seen in the following pictures. By pressing the button entitled "New", the user should pass to the camera GUI, (default Android camera GUI from the device), or the signatures GUI and the Notes GUI (Fig. 14).

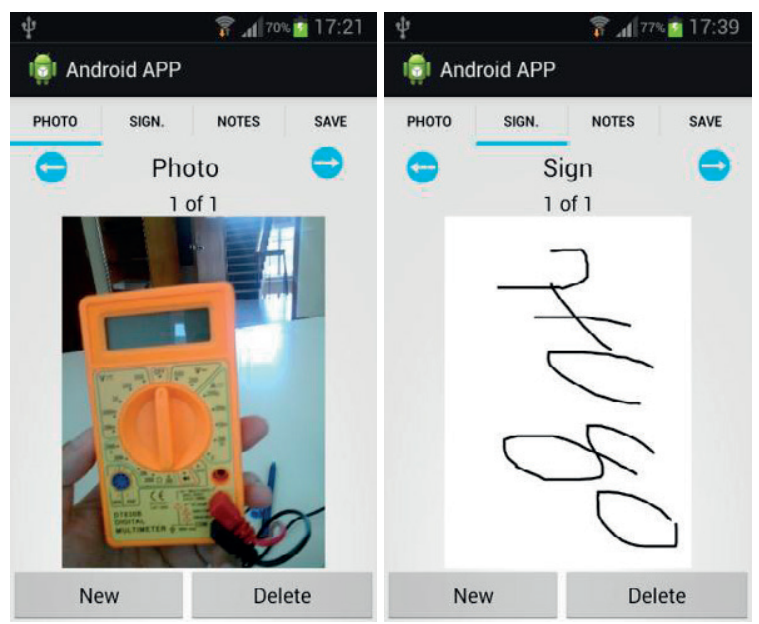

Fig. 13. Camara capture and signature capture GUI on Android.

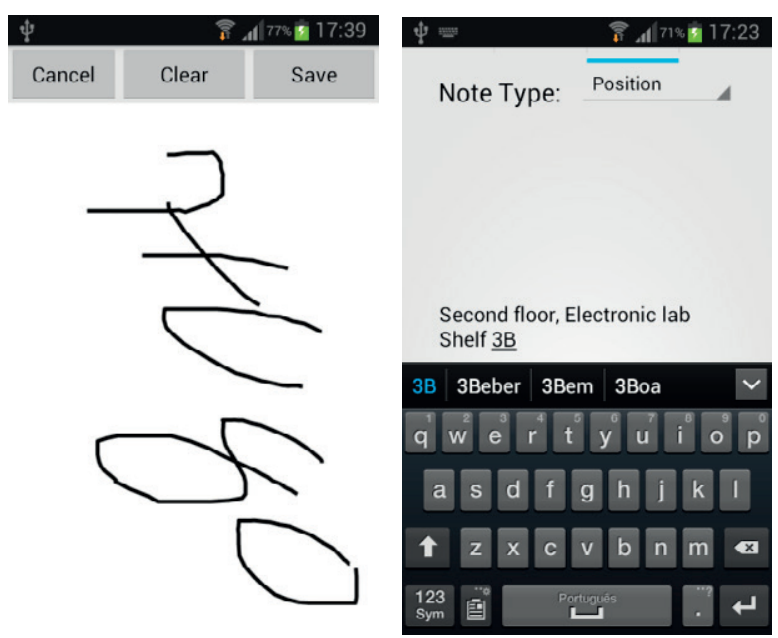

Fig. 14. Signture and Notes GUI

The user should press the "save" tab following data collection. In response, the application should upload all the registered information to the server, notifying the technician of the success or failure of this procedure before returning to stage 2 .

\section{Windows Mobile Implementation}

To implement this application on Windows Mobile it was necessary to use the standard IDE of Microsoft, Microsoft Visual Studio, and all developed code was written in C\#. In order to test and debug, this application used a Datalogic device, more precisely the Datalogic Lynx, (Fig. 15).

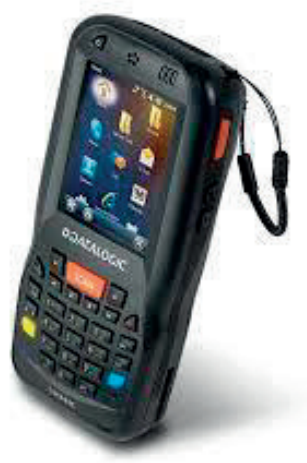

Fig. 15. Datalogic Lynx

The industrial PDA is a mobile device that is capable of withstanding manufacturing environments. Included in the device's hardware is a laser scanner, eliminating the need for a third party software, which is needed for the Android Implementation. Unfortunately, the industrial PDA requires the use of an application programming interface offered by Datalogic to access the scanner and is often much more expensive than conventional Smartphone devices. 
In Fig. 16, it is possible to see the interface that the Windows mobile user would encounter when selecting the equipment catalog; it is similar to that of the Android (stage 1).

\begin{tabular}{|c|c|}
\hline \multicolumn{2}{|l|}{ Call Data Base } \\
\hline - Areas de Negocio & ᄉ \\
\hline † Electrónica & \\
\hline+ Energia & \\
\hline †-Informática & \\
\hline+ Saude & \\
\hline † teste1 & \\
\hline+ teste 2 & \\
\hline+ teste3 & \\
\hline+ teste 4 & \\
\hline t.teste5 & $\checkmark$ \\
\hline Back & Exit \\
\hline
\end{tabular}

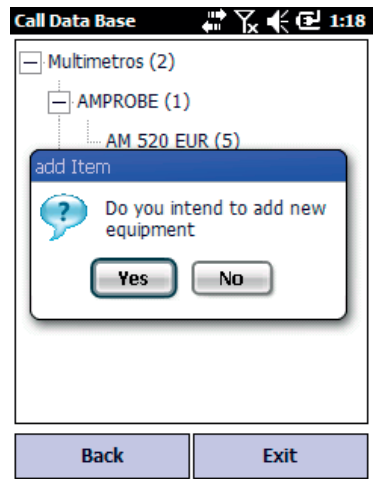

Fig. 16. Display of Equipment List on Lynx

The display Fig. 17 is where the user can trigger the laser scan by pushing the scan button on the device, or manually introducing the commend in the textbox (stage 2).

\section{additem $1: 23$}

Insert Barcode

$\frac{1817767}{\text { check }}$

\section{Next}

Cancel

Fig. 17. Display to introduce the barcode on Lynx

After the database approves the barcode, and the user presses the "Next" button, the application should allow the user to take a photo and capture a signature to authenticate the job; as can be seen in Fig. 18(stage 3).

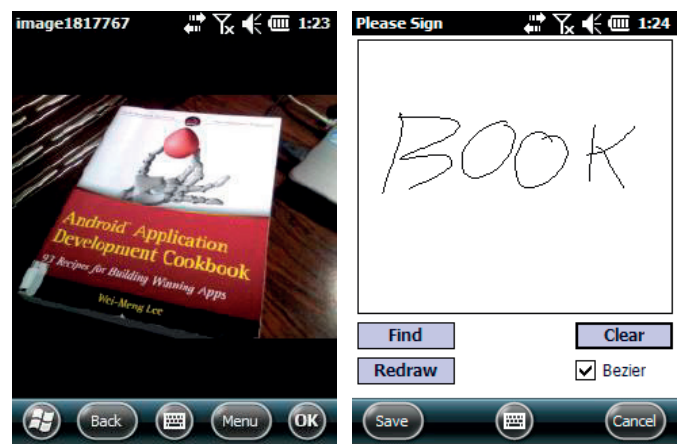

Fig. 18. Camara capture and signature capture GUI on Lynex.

As previously described, the application should upload all data taken to the server and alert whether the upload has been successfully, returning then to stage 2 .

\section{IMPROVEMENTS IN INITIAL MAINTENANCE ORGANIZATION AND LOCALIZATION}

Firstly, the outlined application is intended to improve the cataloging process of stocks and equipment through the automation of this process in an attempt to improve the overall maintenance process.

Secondly, there is the possibility of improving the management of assets since through the database it is possible to obtain several details about assets, conditions, images, location and additional details, ultimately effectively organizing day-to-day maintenance processes.

Finally, the present application demonstrates the endless possibilities of using generic equipment, instead of costly specialized equipment, in the maintenance process by ensuring a substantial reduction in costs.

\section{CONCLUSIONS}

The present research demonstrates the potential and capabilities available through mobile and server applications within the maintenance field by enhancing automation, increasing data accuracy, lowering costs, and simplifying the overall process. The following application demonstrates an ever evolving process as new technological innovation may lead to greater optimization. For example, the GUI interface in both versions may be graphically improved upon to become more user friendly. It is also important to improve the running speed of the application in both the Android and Windows versions. Tests are taking place to interface the tables in the asset management application, and findings demonstrate that Object Maintenance with mobile devices improve the working time of human resources. Future applications may include data collection for hospital Object Maintenance catalogs. 


\section{REFERENCES}

[1] Internet Engineering Task Force (IETF), "The JavaScript Object Notation (JSON) Data Interchange Format," 3 2014. [Online]. Available: http://tools.ietf.org/html/rfc7159. [Acedido em 304 2014].

[2] R. T. Fielding, "CHAPTER 5 - Representational State Transfer (REST)," 2000 [Online]. Available: www.ics.uci.edu/ fielding/pubs/dissertation/rest arch style.htm. [Accessed 25 2014].

[3] R. T. FIELDING and R. N. TAYLOR, "Principled Design of the Modern Web Architecture," $52002 . \quad$ [Online]. Available: www.ics.uci.edu/ taylor/documents/2002-REST-TOIT.pdf. [Accessed 45 2014].

[4] I. RealPage, "RealPage home page," RealPage, Inc, 2014. [Online]. Available: http://www.realpage.com/. [Acedido em 26 2014].

[5] I. Yardi Systems, "Yardi home page," Yardi Systems, Inc, 2014. [Online]. Available: http://www.yardi.com/. [Acedido em 26 2014].
[6] W.-M. Lee, "Android Application Development Cookbook," in Capturing Barcodes, Indianapolis, Indiana, USA, John Wiley \& Sons, Inc., 2013, pp. 319 - 323.

[7] Wasp Barcode Technologies, "Introducing MobileAsset v7," Wasp Barcode Technologies, 2014. [Online]. Available: http://www.waspbarcode.com/asset-tracking/whats-new-v7. [Acedido em $3072014]$.

[8] Wasp Barcode Technologies, "Wasp Barcode Technologies Announces MobileAsset v7, MobileAsset.EDU with iPhone, iPad, Android connectivity," Wasp Barcode Technologies, 2014. [Online]. Available: http://www.waspbarcode.com/about-us/press-release/2014-05-29mobileasset-with-ios-android-connectivity. [Accessed 3007 30].

[9] RealPageMedia, "Keep Your Service Technicians in the Field," RealPage, $12 \quad 4 \quad 2012 . \quad$ [Online]. Available: https://www.youtube.com/watch?v=8m3q0urO6uc. [Acedido em 201407 30]. 